\title{
LINKING ADMINISTRATORS' ROLES IN CAREER PROGRAMS TO PROACTIVE BEHAVIOR AS A DETERMINANT OF EMPLOYEES' PROMOTION OPPORTUNITIES
}

\author{
Azman Ismail ${ }^{1 *}$, Eddy Madiono Sutanto ${ }^{2}$ \\ ${ }^{1}$ Faculty of Economics and Management, University Kebangsaan Malaysia, Malaysia \\ ${ }^{2}$ Faculty of Economics, Petra Christian University, Surabaya, Indonesia. \\ *Corresponding author; Email: azisma08@gmail.com
}

\begin{abstract}
This research examines the relationship between administrators' roles in career programs, proactive behavior and employees' promotion opportunities. Self-administered questionnaires were collected from employees who work in an established private oil and gas firm in West Coast of Peninsular Malaysia. The outcomes of SmartPLS path model analysis demonstrate that the ability of administrators to plan and manage career programs have strongly invoked employees' proactive behavior. As a result, this situation may lead to an enhance employees' promotion opportunities in the organizational sample. Further, this study offers discussion, implications and conclusion.
\end{abstract}

Keywords: Administrators' roles in career programs, proactive behavior, promotion opportunity.

\section{Introduction}

Career program is a main responsibility of human resource development and management. It concerns on the progress of whole aspects of employees' well-being which related to their occupations or professions in organizations (Neary, Dodd, \& Hooley 2015; Guerrero, Jeanblanc, \& Veilleux 2016). In high competitive organizations, career is viewed as a strategic instrument for supporting organizational strategy and culture. To ensure that this aim can be achieved, human resource administrators will usually use a partnership-corporate model to attract support from line administrators to involve in designing a master plan for developing and enhancing employees' career paths in organizations (Stumpf, 2007; Rosen, Slater, \& Johnson 2013; Hornung, Rousseau, Weigl, Muller, \& Glaser, 2014). This cooperation is often done through a committee system where all members will share their times, energies and expertise to thoroughly conduct career needs assessments and results from this assessment process will be used to establish objectives, set up action plans, determine career tools, and formulate career policies and procedures. This master plan will guide line administrators in developing and improving career paths for employees who work in every department/division within an organization (Guerrero et al., 2016; Gucciardi, Caputo, Fregonese, Launcher, \& Sartori, 2017).

A well-designed career master plan helps administrators to appropriately perform their responsibilities: first, determine a balance between workers' careers requirements and the organization's manpower requirements (Antoniu, 2010; Ismail, Daud, \& Madrah 2011; Lips-Wiersma \& Hall, 2007). Second, determine appropriate career instruments in order to help employees to achieve their career goals such as through internal training, formal education, counseling, job rotation, succession plans, work simplification and care the quality of employees' work life in organizations (Chang et al., 2007; Ismail et al., 2011; Koen, Klehe, Van Vianen, Zikic, \& Nauta 2010; Kulkarni, 2013). Third, match workers' interests and capabilities with the organization's current and future transformations through retaining and motivating top talented employees, enhancing engagement and productivity, strengthening the succession plan for competent people, upgrading knowledge transfer and retention, filling internal skill and role gaps, and creating a positive organizational image in an era of knowledge based global economy (Antoniu, 2010; Insala, 2016; Ismail et al., 2011).

An examination of the current literature pertaining to the up-to-date human resource development shows that well-designed career programs will not be able to support their vision and mission if administrators do not have sufficient skills to handle the career programs (Hadjisolomou, 2015). According to an effective manager literature, market winner based organizations need administrators who have highly skills to think, plan and execute transformational process in order to enhance employees' career goals in organizations (Ngima \& Kyongo, 2013; Cheung \& Wong, 2011; Wan Aishah, Azman, \& Raja Rizal Iskandar, 2015; Prieto \& Pe'rez-Santana, 2014). In 
managing career programs, administrators often implement mechanistic and humanistic changes. Mechanistic change refers to the willingness of administrators to redesign job descriptions, promote flexibilities, decentralize decision-making power and provide empowerment so that employees will have more freedom and discretion in simplifying work procedures and methods, planning work schedules based on priority and reducing decision making redtapes in meeting customers' demands and expectations (Husman, 2008; Johnson, Nguyen, Groth, Wang, \& Ng, 2016). Conversely, humanistic change is often related to as administrators put a high value on employees, employees are viewed as valuable and important assets, and catalyst for transforming organizations in order to accomplish their vision and missions. Under this strategic perspective, administrators attempt to understand and respect diversity of employees' motives and expectations, motivate employees to acquire necessary knowledge and skills, implement multi-rater assessments, guide employees to support organizational strategies and objectives, and inspire employees work ethically by showing their good examples in organizations (Bass \& Avolio, 1990; Ismail, Mohamad, Mohamed, Rafiuddin, \& Zhen, 2010; Stumpf, 2007; Gilpin-Jackson, 2017).

Recent studies about effective career management highlight that the ability of administrators to appropriately design and manage career programs may have a significant impact on career outcomes, especially proactive behavior (Marinova, Peng, Lorinkova, Dyne, \& Chiaburu, 2015; Van Der Zee, 2016) and promotion opportunity (Zhang, 2014; Ali \& Zia-ur-Rehman, 2014; Dahling \& Lauricella, 2016). In a career management perspective, proactive behavior is generally defined as employees have different characters such self-directed and future oriented behavior. If employees have high proactive behavior, this may enhance their job motivations, capabilities in making planning, awareness and sensitivity to situational changes, abilities to generate new ideas and manage emotions, as well as abilities to use positive actions in enhancing performance and achieving career goals in organizations (Bateman \& Crant, 1993; Crant, 2000; Fay \& Freese, 2001; Wu \& Parker, 2014). Conversely, promotion opportunity is broadly defined as an advancement of employees in gaining higher positions in their organizations (Stumpf, 2007; Takahashi, 2006). This promotion opportunity will invoke employee perceptions that their employers highly appreciate and recognize employees' contributions and/or performance by giving chances to carry out more challenging and bigger duties and responsibilities in organizations (Breland et al., 2007; Naveed, Usman, \& Bushra, 2011; Takahashi, 2006; Hamukwaya \& Yazdanifard, 2014).

Interestingly, proactive behavior has been a crucial issue when many career management literature published in the early of $21^{\text {st }}$ century reveals that effect of administrators' roles in career programs on promotion opportunity is indirectly affected by employees' proactive behavior (Said, Rasdi, Samah, Silong, \& Sulaiman, 2015). Even though the nature of this relationship is interesting, the role of proactive behavior as an influential mediating variable has been ignored in the organizational career research literature. Many researchers debate that this condition may be caused by several reasons: first, many earlier studies on human resource management have much emphasized the internal properties of career program, such as conceptual definitions, objectives, forms, and advantages of administrators' roles in planning and implementing career programs in organizations (Brandt, 2012; Ismail, Madrah, Aminudin, \& Ismail, 2013; Browning, Thompson, \& Dawson, 2014). Second, many preceding researches on career management have much utilized a simple correlation analysis method to describe employee attitudes toward administrators' roles in career programs and/or assess effect of administrators' roles in career programs on particular dimensions of career outcomes such as proactive behavior and promotion opportunity. Findings from these studies have largely predicts the strength of association between administrators' roles in career programs and the career outcomes (Neary et al., 2015).

Third, most previous researches on proactive behavior have used personality theories where it is seen as an important dispositional construct (e.g., differences between individual characters). This perspective ignores the role of proactive behavior as an important catalyst in the person-situation-behavior relationship. Thus, findings from this study have not capable to judge the role of proactive behavior as an influential mediating variable in between administrators' roles in career programs and employees' promotion opportunities (Bateman \& Crant, 1993; Crant, 2000; Kong, 2013). Consequently, the above study approaches have much produced general findings and this may not sufficient to be used as useful recommendations by practitioners in understanding the concept of administrators' roles in career programs, and formulating credible career development methods in order to maintain and support organizational strategic business vision and missions in an era of borderless world (Guerrero et al., 2016; Kong, 2013; Wan Aishah et al., 2015). Thus, this situation inspires 
the researchers to fill in the gap of literature by assessing the mediating effect of proactive behavior in the relationship between administrators' roles in career programs and employees' promotion opportunities.

The present study was conducted to answer two primary objectives: first, is to measure the relationship between administrators' roles in career programs and proactive behavior. Second, is to measure the relationship between administrators' roles in career programs, proactive behavior and promotion opportunity. The structure of this paper discusses five important aspects: literature review, methodology, findings, discussion and implications, and conclusion.

Relationship between administrators' roles in career programs and proactive behavior is consistent with the notion of leadership theory. For example, House and Mitchell's (1974) Path Goal Theory describes that the ability of leaders to determine the correct paths may motivate employees to accomplish their objectives. Moreover, Bass and Avolio's (1990) Transformational Leadership Theory suggests that the readiness of leaders to implement transformation process based on social relations in performing daily work may enhance employees' positive behavior. Further, Graen and Uhl-Bien's (1995) Leadership Making Model addresses that quality of relationship between leaders and followers is developed based on good treatments may enhance positive subordinate behavior (Bauer \& Erdogan, 2015; Deluga, 1998; Liden, Sparrowe, \& Wayne, 1997). Application of these theories in career administration shows that the notion of good leadership practice such as fair treatment, path-goal, transformation and quality of interaction is normally translated into administrators' roles in career programs. The notion of these theories is consistent with the career administration research literature (Searle, 2011; Brandt, 2012; Marinova et al., 2015).

Some important previous studies were conducted using a direct effects model to assess administrators' roles in career programs in the different organizational samples, such as perceptions of 391 principals who attended the professional development programs at two multinational professional services organizations (Stumpf, 2007), 523 public servants at a state government agency in US (Searle, 2011), 131 workers in the Netherlands (Brandt, 2012), 28402 meta-analytic tests (Marinova et al., 2015), 205 adult citizens of the United States (Dahling \& Lauricella, 2016), 146 trainees from the financial sector (Van Der Zee, 2016) and 277 employees in a wide variety of jobs organized mainly in a traditional functional structure that included research and development, manufacturing, warehousing, sales and marketing, and general administration in China (Zhang, 2014). The results of these surveys showed that the ability of administrators to properly plan and management career programs had enhanced employees' proactive behavior (Searle, 2011; Brandt, 2012; Marinova et al., 2015; Van Der Zee, 2016), and promotion opportunities (Stumpf, 2007; Ali \& Zia-ur-Rehman, 2014; Dahling \& Lauricella, 2016: Zhang, 2014).

The literature has been used as foundation of developing a conceptual framework as exhibited in Figure 1.

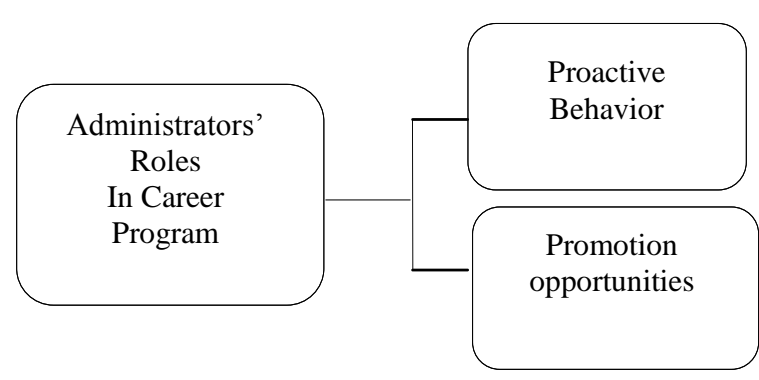

\section{Figure 1}

Conceptual Framework

Based on the framework, it was hypothesized that:

$H_{l}$ : There is a positive relationship between administrators' roles in career programs and employees' proactive behavior.

$\mathrm{H}_{2}$ : There is a positive relationship between administrators' roles in career programs and employees' promotion opportunities.

Relationship between of administrators' roles in career programs, proactive behavior and employees' promotion opportunities gained strong support from the main idea of proactive behavior theory (Bandura, 1977, 1986; Bateman \& Crant, 1993; Crant, 2000). Traditionally, proactive behavior concept has been first highlighted by Briggs and Cheek's (1980) Big Five Theory, which only explain as an important personal dispositional element, but its impact on employee outcomes has been ignored in career administration studies (Bateman \& Crant, 1993; Crant, 2000). Then, this theory has been upgraded by Crant (2000) to develop a specific Proactive Behavior Theory, which reveals that employees with high proactive behavior have sufficient competencies (e.g., necessary knowledge, up to date skills, latest cognitive, affective and psychomotor abilities, positive attitudes and other current capabilities) and this will enable them to easily adapt, control and/or create good working environments. As a result, this environment may induce positive employee outcomes. Appli- 
cation of this theory in career administration shows that proactive behavior is an important mediating variable in between administrators' roles in career programs and employees' promotion opportunities (Kong, 2013; Azman et al., 2016; Said et al., 2015). The main idea of the theory is consistent with the career administration research literature.

Further, several advanced studies were conducted using an indirect effects model to evaluate employees' proactive behavior in various organizational samples, such as perceptions of 325 academics from Malaysian research universities. The results of these surveys displayed that the ability of administrators to appropriate plan and manage career programs had strongly invoked employees' proactive behavior. Consequently, this positive behavior could lead to an enhance employees' promotion opportunities in the respective organizations (Said et al., 2015).

The literature has been used as the important basis for developing a conceptual schema as exhibited in Figure 2.

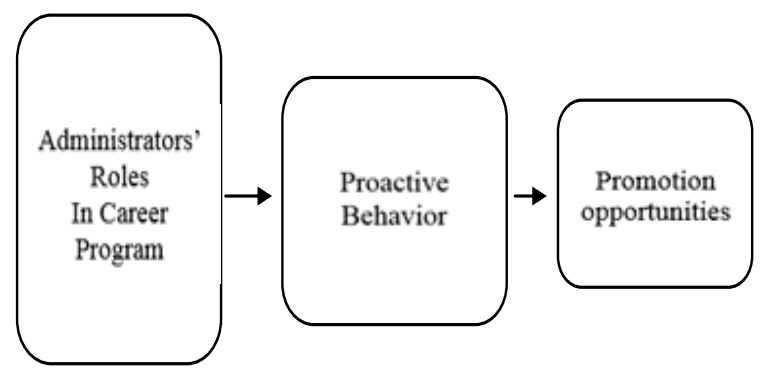

Figure 2

Conceptual Schema

Based on the schema, it can be hypothesized that:

$H_{3}$ : Effect of administrators' roles in career programs on employees' promotion opportunities is mediated by employees' proactive behavior.

\section{Research Method}

\section{Research Design}

A cross-sectional research design was employed because it allowed the researchers to incorporate the career administration literature and the actual survey as the main method to gather data for this study. Application of this method in management research may help the researchers to collect precise data, less bias, and high quality data (Creswell, 2012; Sekaran, 2000). This study was done at an established private oil and gas firm in West Coast of Peninsular Malaysia. For confidential reasons, the name of this organization is kept anonymous. The top manage- ment of this organization has organized leadership development programs to impart mechanistic and humanistic oriented leadership style to administrators who work in different departments/sections, and they are also given autonomous power to plan and implement career development programs for professional, semi-professional and operation workers in the organizations. Even though administrators have taken proactive actions to achieve the objectives of career programs, the effectiveness has not been empirically investigated. Therefore, this situation has inspired the researchers to further explore the issue. At the initial stage of this research, a survey questionnaire was developed based on the career administration literature. Further, the back translation technique was employed to translate the survey questionnaires into Malay and English versions in order to increase the validity and reliability of the research results (Cresswell, 2012; Sekaran, 2000).

\section{Measures}

The survey questionnaire has four major parts: first, administrators' roles in career programs (ARCP) had 11 items adapted from career administration literature (Saragih, 2011; Mack, 2012; Callow, Smith, Hardy, Arthur, \& Hardy, 2009; Rank, 2006). The dimensions used to measure this construct were task autonomy and leadership. Second, proactive behavior (PROB) had 7 items adapted from career administration related proactive behavior (Searle, 2011; Gevorkian, 2011). The dimensions used to measure this construct were career management behavior, proactive personality and networking. Finally, promotion opportunity (PROT) had 8 items adapted from career program related promotion (Forret \& Dougherty, 2004; James, 2000; Sutton, 2006). The dimensions used to measure this construct were policy, procedure, and criteria. The whole items used in the questionnaire were assessed using a 7-item scale ranging from "strongly disagree/dissatisfied" (1) to "strongly agree/satisfied" (7). Respondent characteristics were treated as controlling variables because this study concerned on worker attitudes.

\section{Sample}

The targeted population is employees in the organization. A purposive sampling plan was employed to distribute 300 survey questionnaires to employees who work in all departments/divisions within the organization. This sampling plan was chosen because the head of organization had not provided the list of registered employees to the 
researchers for confidentiality reasons. This condition has not allowed the researchers to choose participants using a random technique. Of the number, 118 (39 percent) usable questionnaires were successfully collected by the researchers. The survey questions were answered by participants based on their consent and a voluntarily basis. The adequacy of this sample is measured based on the rule of thumb, which indicates "the sample size should be equal to larger of 10 times the largest number of structural paths directed at a particular construct in the structural model" (Hair, Hult, Ringle, \& Sarstedt, 2017), and "the measurement models have an acceptable quality of terms of outer loading (i.e., loadings should be above the common threshold of 0.70)" (Hair et al., 2017). The nature of this sample has met the above criteria, so it can be used to test the hypothesized model.

\section{Data Analysis}

The SmartPLS was utilized to assess the survey questionnaire data because it can deliver latent construct scores, overcome the problem of small sample size, estimate a complex model that has many latent constructs and manifest variables, meet assumptions about the distribution of variables and error terms, and handle reflective and formative measurement model (Henseler, Ringle, \& Sarstedt 2015). The procedure of data analysis is: first, the instrument is evaluated to determine the standards of validity and reliability analyses. Second, the structural model is evaluated by examining the path coefficients using standardized betas $(\beta)$ and $t$ statistics $(t>1.65$ [one tail] for the direct effects model) and $t>1.96$ [two tail] for the mediating model). Third, the value of $R^{2}$ for an endogenous variable is used as an indicator of the overall predictive strength of the model based on the criteria: 0.26 (substantial effect), 0.13 (moderate effect), 0.02 (weak effect) (Cohen, 1988). Four, Zhao, Lynch, and Chen's (2010) type of mediating effect procedure is used to determine the size of mediating effect based on the criteria: complementary mediation (partial mediation), competitive mediation (partial mediation), indirect only (full mediation), direct-only (no mediation), and no effect (no mediation). Five, the value of $Q^{2}$ of exogenous latent variable is used to evaluate the model's predictive relevance based on the criteria: 0.02 (weak effect), 0.15 (medium effect) and 0.35 (large effect) (Hair et al., 2017). Finally, the value of $f^{2}$ of endogenous latent variable is used to determine the effect size of independent variable in the model based on the criteria: 0.02 (weak effect), 0.15 (medium effect) and 0.35 (large effect) (Hair et al., 2017).

\section{Results and Discussion}

\section{Profiles of Respondents}

Table 1 shows that the majority respondents were male (57.6 percent), aged between 25 to 34 years old (65.3 percent), degree holders (45.8 percent), employyees who served from 5 to 14 years (55.1 percent), employees who had monthly salaries starting from RM 4000 and above (55.1 percent), and married employees (72.0 percent).

The results of confirmatory factor analysis show that the values of average variance extracted (AVE) for ARCP (0.673), PROB (0.588) and PROT (0.739) were greater than 0.5 , indicating that these constructs met the acceptable standard of convergent validity (Fornell \& Larcker 1981). Meanwhile, the values of AVE square root in diagonal for ARCP (0.820), PROB (0.767) and PROT (0.860) were greater than the squared correlation with other constructs in offdiagonal, showing that these constructs met the acceptable standard of discriminant validity (Hair et al., 2017; Henseler, Ringle, \& Sinkovics, 2009).

Factor loadings for the items that represent ARCP (0.753 to 0.879), PROB (0.730 to 0.786) and PROT ( 0.819 to 0.903$)$ were greater than other items in the different constructs. These loadings stronger on their own constructs in the model, and greater than 0.70 were considered adequate (Hair et al., 2017). In sum, the measurement model has met the validity criteria. Further, the values of composite reliability for ARCP (0.958), PROB (0.909) and PROT (0.958) were greater than 0.7 , indicating that the instrument used in this study had high internal consistency (Hair et al., 2017).

The mean values for ARCP, PROB and PROT were from 4.392 to 5.841 , showing that the levels of all constructs ranging from high (4) to the highest level (7). Meanwhile, the values of variance inflation factor for the connections: a) between the independent variable (i.e., ARCP) and the dependent variable (i.e., PROT) was 1.00; and b) between the mediating variable (i.e., $\mathrm{PROB}$ ) and the dependent variable (i.e., PROT) was 1.00. These values were less than 5.0, showing that the data were not influenced by serious collinearity problem (Hair et al., 2017). In overall, the confirmatory factor analysis results further confirm that the instrument has satisfactorily met the criteria of validity and reliability analyses. 
Table 1

Participant Characteristics

\begin{tabular}{|c|c|c|}
\hline $\begin{array}{c}\text { Participant } \\
\text { Characteristics }\end{array}$ & Sub-Profile & $\begin{array}{c}\text { Percentage } \\
(\%)\end{array}$ \\
\hline \multirow[t]{2}{*}{ Gender } & Male & 57.6 \\
\hline & Female & 42.4 \\
\hline \multirow[t]{5}{*}{ Age } & Below 25 years & 2.5 \\
\hline & 25-34 years & 65.3 \\
\hline & $35-44$ years & 22.0 \\
\hline & $45-54$ years & 9.3 \\
\hline & 55 years and above & 0.8 \\
\hline \multirow[t]{4}{*}{ Education } & LCE/SRP & 1.7 \\
\hline & MCE/SPM & 8.5 \\
\hline & HSC/STPM/ Diploma & 35.5 \\
\hline & Degree & 45.8 \\
\hline \multirow[t]{4}{*}{ Position } & Master/PhD & 8.5 \\
\hline & Management \& & \\
\hline & Professional Group & 63.6 \\
\hline & Supporting Group & 36.4 \\
\hline \multirow[t]{4}{*}{ Length of Service } & Below 5 years & 32.2 \\
\hline & $5-14$ years & 55.1 \\
\hline & 15-24 years & 9.3 \\
\hline & 25 years and above & 3.4 \\
\hline \multirow[t]{4}{*}{ Monthly Salary } & Less than RM 1000 & 1.7 \\
\hline & RM 1000-RM2499 & 9.3 \\
\hline & RM 2500-RM3999 & 38.9 \\
\hline & RM 4000 and above & 50.0 \\
\hline \multirow[t]{2}{*}{ Marital Status } & Single & 27.9 \\
\hline & Married & 72.0 \\
\hline \multicolumn{3}{|l|}{ Note: } \\
\hline \multicolumn{3}{|c|}{$\begin{aligned} \text { SPM/MCE : } & \text { Sijil Pelajaran Malaysia/Malaysia Certifi- } \\
& \text { cate of Education. }\end{aligned}$} \\
\hline $\begin{array}{ll}\mathrm{STPM} / \mathrm{HSC}: & \mathrm{S} \\
\mathrm{S}\end{array}$ & $\begin{array}{l}\text { Tinggi Pelajaran } \mathrm{M} \\
\text { ol Certificate. }\end{array}$ & aysia/Higher \\
\hline $\mathrm{RM}$ & aysian Ringgit. & \\
\hline
\end{tabular}

Table 2 displays that the presence of ARCP in the analysis had contributed 35 percent in the variance of PROB. This outcome shows that it provides strong support for the model. Further, the result of testing the research hypothesis displayed that ARCP was significantly related to PROB $(B=0.589 ; t=7.637)$, therefore $H_{l}$ was supported. This result confirms that ARCP act as important predictor of PROB in the organizations. Further, effect size $\left(f^{2}\right)$ and blindfolding $\left(Q^{2}\right)$ were tested using a Blindfolding procedure. The results of testing effect size showed that the $f^{2}$ value for ARCP (0.532) was larger than 0.35 (Hair et al., 2017), showing that it provides the large effect on PROB. The results of blindfolding showed that the value of $Q^{2}$ for PROB was 0.184 , showing that it was greater than zero for the reflective endogenous latent variable. This result has predictive relevance (Hair et al., 2017).

Table 2

Results of Testing $H_{I}$

\begin{tabular}{ll}
\hline Hypothesis: & $\begin{array}{l}\text { Relationship between } \\
\text { ARCP and PROB }\end{array}$ \\
\hline Beta & 0.589 \\
$T$-Statistics & 7.637 \\
$f^{2}$ & 0.532 \\
$R^{2}$ & 0.347 \\
$Q^{2}$ & 0.184
\end{tabular}

Note: Significant at $* t>1.65$ (One Tail Testing).

Table 3 displays that the presence of ARCP in the analysis had contributed 15 percent in the variance of PROT. This outcome shows that it provides moderate support for the model. Further, the result of testing the research hypothesis displayed that ARCP was significantly related to PROT $(B=0.392$; $t=5.456$ ), therefore $\mathrm{H}_{2}$ was supported. This result confirms that ARCP act as important predictor of PROT in the organizations.

Further, effect size $\left(f^{2}\right)$ and blindfolding $\left(Q^{2}\right)$ were tested using a Blindfolding procedure. The results of testing effect size showed that the $f^{2}$ value for ARCP (0.182) was from 0.15 to 0.35 (Hair et al., 2017), showing that it provides the medium effect on PROT. The results of blindfolding showed that the value of $Q^{2}$ for PROT was 0.097 , showing that it was greater than zero for the reflective endogenous latent variable. This result has predictive relevance (Hair et al., 2017).

Table 3

Results of Testing $\mathrm{H}_{2}$

\begin{tabular}{ll}
\hline Hypothesis: & $\begin{array}{l}\text { Relationship between } \\
\text { PROB and PROT }\end{array}$ \\
\hline Beta & 0.392 \\
$T$-Statistics & 5.456 \\
$f^{2}$ & 0.182 \\
$R^{2}$ & 0.154 \\
$Q^{2}$ & 0.097 \\
\hline
\end{tabular}

Note: Significant at $* t>1.65$ (One Tail Testing).

Table 4 displays that the presence of ARCP and $\mathrm{PROB}$ in the analysis had contributed 13 percent in the variance of PROT. This outcome shows that it provides moderate support for the model. Further, the result of testing the research hypothesis displayed that 
relationship between ARCP and PROB was significantly related to PROT $(B=0.366 ; t=4.943)$, therefore $\mathrm{H}_{3}$ was supported. This result confirms that PROB does act as an important mediating variable in the relationship between ARCP and PROT in the organizations. In terms of the type of mediating effect, PROB has played important roles as a direct only non-mediation effect in the hypothesized model (Zhao et al., 2010). Further, effect size $\left(f^{2}\right)$ and blindfolding $\left(Q^{2}\right)$ were tested using a Blindfolding procedure. The results of testing effect size showed that the $\mathrm{f}^{2}$ value for ARCP was bigger than 0.35 (Hair et al., 2017), showing that it provides the large effect on PROB. Conversely, the $f^{2}$ value for PROB was from 0.15 to 0.35 (Hair et al., 2017), showing that it provides the medium effect on PROT. The results of blind folding showed that the value of $Q^{2}$ for PROT was 0.084 , showing that it was greater than zero for the reflective endogenous latent variable. This result has predictive relevance (Hair et al., 2017).

\section{Table 4}

\section{Results of Testing $\mathrm{H}_{3}$}

\begin{tabular}{lll}
\hline Hypothesis & $\begin{array}{l}\text { Relationship between } \\
\text { ARCP and PROB }\end{array}$ & $\begin{array}{l}\text { Relationship } \\
\text { between PROB and } \\
\text { PROT }\end{array}$ \\
\hline Beta & 0.586 & 0.366 \\
$T$-Statistics & 7.150 & 4.943 \\
$f^{2}$ & 0.523 & 0.155 \\
$R^{2}$ & 0.343 & 0.134 \\
$Q^{2}$ & 0.186 & 0.084 \\
\hline
\end{tabular}

Note: Significant at $* t>1.96$ (Two Tail Testing).

\section{Discussion and Implications}

The findings of this study reveal that PROB does act as an important mediating variable in the relationship between ARCP and PROT in the organization. In the context of this study, senor management have collaborated and cooperated with line managers to plan and administer career programs based on the broad policies and procedures as established by their stakeholders. The majority respondents view that the levels of ARCP, PROB and PROT are high. This condition explains that the ability of administrators to properly plan and manage career programs will strongly invoke employees' proactive behavior. Consequently, this positive behavior may lead to an enhance employees' promotion opportunities in the organizations.

This study provides three major implications: theoretical contribution, robustness of research methodology, and contribution to practitioners. With respect to theoretical contribution, the outcomes of this study have enhanced our understanding that PROB has successfully mediated the effect of ARCP on PROT in the organization. This outcome is consistent with the notion of Crant (2000) Proactive Behavior theory, which reveals that the ability of administrators to appropriately plan and manage career programs will strongly invoke employees' proactive behavior. As a result, this situation may enhance employees' promotion opportunity in the organizations. This outcome also has supported and extended studies by Said $e t a l$. (2015). With respect to the robustness of research methodology, the survey questionnaire data employed in this study had satisfied the requirements of validity and reliability analyses. This condition may lead to produced accurate and reliable research results.

In terms of practical contribution, this study provides several important recommendations that may be used as useful guidelines by practitioners to improve the administration of career programs in competitive organizations. This purpose may be executed if top management consider the following aspects: firstly, helping relationships and positive support should be encouraged between leaders and followers; and between followers in order to achieve organizational goals. Second, coaching programs should be planned to train management employees to be good coach and enhance their capabilities to use appropriate coaching techniques in teaching and facilitating followers to perform daily work. Third, participative decision making style should be actively practiced to encourage communication openness, obtain brilliant suggestions and feedback from employees, as well as strengthen caring and cooperation cultures in improving employees' work-life happiness. Four, recruitment and selection policies should focus on hiring candidates who have good personalities, relevant knowledge and good track records in previous working experiences to fill in vacancies in critical positions. These candidates' competencies may not only perform their job, but can be utilized to coach, mentor and counsel junior managers and supporting employees in accomplishing organization and job targets. If these suggestions are given attention this may strongly stimulate employees to perform organizational career goals.

\section{Conclusion}

This study tested a conceptual schema developed based on the career program research literature. Confirmatory factor analysis showed that the instrument used in this study met the requirements of validity and reliability analyses. The findings of 
SmartPLS confirmed that proactive behavior has successfully mediated the effect of administrators' roles in career programs on employees' promotion opportunities in the organizations. This finding is consistent with and has broadened the previous studies mostly published in Western countries. Thus, recent research and practice within human resource development and management need to view proactive behavior as the critical features of the career program domain. This study further suggests that the ability of administrators to appropriately design and manage career programs will strongly enhance subsequent positive career outcomes (e.g., career goals and career satisfaction). Therefore, these positive outcomes may lead to maintaining and supporting the organizational strategy and objectives in an era of global economy.

This study has few methodological and conceptual limitations. Firstly, the data was taken using a cross sectional research design whereby it may not adequate to assess detail study sample profile and cannot make a comparison within the sample. Secondly, this study does not investigate the correlation between specific dimensions for administrators' roles in career programs, proactive behavior and promotion opportunity. Thirdly, other specific dimensions for administrators' roles in career programs, proactive behavior and promotion opportunity are neglected in this study. Finally, this study used a purposive sampling plan to collect data at an oil and gas firm in Peninsular Malaysia. These limitations may decrease the ability of generalizing the findings of this study to various organizational settings.

This study provides some important suggestions to strength future study. Firstly, several demographic variables such as gender, age, education and position should be further discovered because they may show significant perspectives in understanding how these variables may influence employees' work life wellbeing. Secondly, a longitudinal study is another method that may be considered because it can clearly explain detail the patterns of change, direction and, magnitude of cause-effect relationships between research variables. Thirdly, a future study should be done at more than one organizations and outcomes from this study can be used to make comparison in order to highlight meaningful findings. Four, other dimensions of administrators' roles in career programs such as empowerment, method and networking should be investigated because they have extensively been recognized as significant antecedents of proactive behavior and promotion opportunity. Five, specific dimensions of proactive behavior such as positive traits and social networking should be measured because they have broadly been acknowledged as influential mediators in the relationship between administrators' roles in career programs and career advancement. Finally, other specific dimensions of promotion opportunity such as monetary rewards, non-monetary rewards and position power should be evaluated because they are found as a significant outcome of the relationship between administrators' roles in career programs and proactive behavior. The importance of these matters needs to be further discovered in future research.

\section{References}

Ali, N. \& Zia-ur-Rehman, M. (2014). Impact of job design on employee performance, mediating role of job satisfaction: A study of FMCG's sector in Pakistan. International Journal of Business and Management, 9(2), 70-79.

Antoniu, E. (2010). Career planning process and its role in human resource development. Annals of the University of Petroşani, Economics, 10(2), 13-22.

Bandura, A. (1977). Self-efficacy: Toward a unified theory of behavioral change. Psychological Review, 84, 191-215.

(1986). Social foundations of thought and action: A social cognitive theory. Englewood Cliffs, NJ: Prentice-Hall.

Bass, B. M. \& Avolio, B. J. (1990). The implications of transactional and transformational leadership for individual, team, and organizational development. International Business \& Economics Research Journal, 3(8).

Bateman, T. S. \& Crant, J. M. (1993). The proactive component of organizational behavior: A measure and correlates. Journal of Organizational Behavior, 14(2), 103-118.

Bauer, N. T. \& Erdogan, B. (2015). The Oxford handbook of leader-member exchange. New York, NY 10016: Oxford University Press.

Brandt, A. (2012). The relationship between transformational leadership and proactive behavior, and the role of meaningfulness and stress. Master thesis. Faculteit Economie En Bedrijfskunde.

Briggs, S. \& Cheek, K. (1980). The frequency concept of disposition: Dominance and prototypically dominant acts. Journal of Personality, 4 , 379-392.

Browning, L., Thompson, K., \& Dawson, D. (2014). Developing future research leaders: Designing early career researcher programs to enhance track record. International Journal for Researcher Development, 5(2), 123-134. 
Callow, N., Smith, M. J., Hardy, L., Arthur, C. A., \& Hardy, J. (2009). Measurement of transformational leadership and its relationship with team cohesion and performance level. Journal of Applied Sport Psychology, 21, 395-412.

Cheung, M. F. Y. \& Wong, C. S. (2011). Transformational leadership, leader support, and employee creativity. Leadership \& Organization Development Journal, 32(7), 656-672.

Cohen, J. (1988). Statistical power analysis for the behavioral sciences (2nd edition). Hillsdale, NJ: Lawrence Erlbaum.

Crant, J. M. (2000). Proactive behavior in organizations. Journal of Management, 26(3), 435-462.

Creswell, J. W. (2012). Educational research: planning, conduct, and evaluating quantitative and qualitative research (4th edition). Boston: Pearson.

Dahling, J. J. \& Lauricella, T. K. (2016). Linking job design to subjective career success: A test of self-determination theory. Journal of Career Assessment, 1-18.

Deluga, R. J. (1998). Leader-member exchange quality and effectiveness ratings: the role of subordinate-supervisor conscientiousness similarity. Group \& Organization Management, 23(2), 189-216.

Fay, D. \& Freese, M. (2001). The concept of personal initiative: An overview of validity studies. Human Performance, 14(1), 97-124.

Fornell, C., \& Larcker, D. F. (1981). Evaluating structural equation models with unobservable variables and measurement error. Journal of Marketing Research, 18, 39-50.

Forret, M. L. \& Dougherty, T. W. (2004). Networking behaviors and career outcomes: Differences for men and women? Journal of Organizational Behavior 25, 419-437.

Gevorkian, M. (2011). Relationships between proactive personality, networking, career satisfaction, and performance perceptions. Unpublished Doctor of Philosophy Thesis., Faculty of the Marshall Goldsmith School of Management Organizational Psychology division, San Diego Alliant International University.

Gilpin-Jackson, Y. (2017). Participant experiences of transformational change in large-scale organization development interventions (LODIs). Leadership \& Organization Development Journal, 38(3), 419-432.

Graen, G. B. \& Uhl-Bien, M. (1995). The Relationship-based approach to leadership: Development of LMX theory of leadership over 25 years: Applying a multi-level, multi domain perspective. Leadership Quarterly 6(2), 219-247.
Gucciardi, F., Caputo, A., Fregonese, C., Launcher, V., \& Sartori, R. (2017). European journal of training and development (EJTDS). EuropeanAmerican Journal, 41(1), 67-82.

Guerrero, S., Jeanblanc, C., \& Veilleux, M. (2016). Development idiosyncratic deals and career success. Career Development International, 2l(1), 19-30.

Hadjisolomou, A. (2015). Managing attendance at work: The role of line managers in the UK grocery retail sector. Employee Relations 37(4), 442-458.

Hair, J. F., Hult, G. T. M., Ringle, C. M., \& Sarstedt, M. (2017). A primer on partial least squares structural equation modeling (PLS-SEM). Second Edition. Los Angeles, Sage.

Hamukwaya, S. I. \& Yazdanifard, R. (2014). How a proper performance related reward system can contribute to work performance excellence. Journal of Business and Management, 2, 189194.

Henseler, J., Ringle, C. M., \& Sarstedt, M. (2015). A new criterion for assessing discriminant validity in variance-based structural equation modeling. Journal of the Academy Marketing Science 43, 115-135.

Henseler, J., Ringle, C. M., \& Sinkovics, R. R. (2009). The use of the partial least squares path modeling in international marketing. New Challenges to International Marketing Advances in International Marketing 20, 277-319.

Hornung, S., Rousseau, D. M., Weigl, M., Muller, A., \& Glaser, J. (2014). Redesigning work though idiosyncratic deals. European Journal of Work and Organizational Psychology, 23(4), 608626.

House, R. J. \& Mitchell, R. R. (1974). Path-goal theory of leadership. Journal of Contemporary Business, 3, 81-97.

Insala. (2016). Why Career Development for Your Employees? Retrieved on Oct 6, 2016 from http://www.insala.com/career-developmentbene fits.asp.

Ismail, A., Daud, N. G., \& Madrah, H. (2011). Relationship between career program characteristics and job satisfaction in a city based local authority. Scientific Annals of the "Alexandru Ioan Cuza" University of Iasi, Economic Sciences section the Romanian Economic Journal, LVIII, 269-280.

Ismail, A., Madrah, H., Aminudin, N., \& Ismail, Y. (2013). Mediating role of career development in the relationship between career program and personal outcomes. Makara Seri Sosial Humaniora, 17(1), 43-54. 
Ismail, A., Mohamad, H. M., Mohamed, H. A. B., Rafiuddin, N. M., \& Zhen, K. W. P. (2010). Transformational leadership and transactional leadership styles as a predictor of individual outcomes. Theoretical and Applied Economics, XVII, 6(547), 89-104.

Ismail, A., Nowalid, W. A. W. M., \& Bakar, R. A. (2016). Proactive behavior as a mediator of the relationship between career management and career satisfaction. Jurnal Pengurusan, 48, 99110.

James, E. (2000). Race-related differences in promotion and support: Underlying effects of human and social capital. Org Science 11, 493-508.

Johnson, A., Nguyen, H., Groth, M., Wang, K., \& Ng. J. L. (2016). Time to change: A review of organizational culture change in health care organizations. Journal of Organizational Effectiveness: People and Performance, 3(3), 265288.

Koen, J., Klehe, U. C., Van Vianen, A. E. M., Zikic, J., \& Nauta, A. (2010). Job-search strategies and reemployment quality: The impact of career adaptability. Journal of Vocational Behavior, 77(1), 126-139.

Kong, H. (2013). Relationships among work-family supportive supervisors, career competencies, and job involvement. International Journal of Hospitality Management, 33, 304-309.

Kulkarni, P. P. (2013). A Literature review on training \& development and quality of work life. International Refereed Research Journal, 4(2).

Liden, R. C., Sparrowe, R. T., \& Wayne, S. J. (1997). Leader-member exchange theory: The past and potential for the future. Research in personnel and human resources management, 15, 47-119.

Lips-Wiersma, M. \& Hall, D. T. (2007). Organizational career development is not dead: A case study on managing the new career during organizational change. Journal of Organizational Behavior, 28, 771-792.

Mack, K. G. (2012). Conscientiousness as a moderator of the relationship between work autonomy and job satisfaction. PhD Thesis, Portland State University.

Marinova, S. V., Peng, C., Lorinkova, N., Dyne, L. V., \& Chiaburu, D. (2015). Change-oriented behavior: A meta-analysis of individual and job design predictors. Journal of Vocational Behavior, 88, 104-120.

Naveed, A., Usman, A., \& Bushra, F. (2011). Promotion: A predictor of job satisfaction: A study of glass industry of Lahore (Pakistan). International Journal of Business and Social Science, 2(16), 301-305.
Neary, S., Dodd, V. \& Hooley, T. (2015). Understanding career management skills: findings from the first phase of the CMS leader project. Derby: International Centre for Guidance Studies, University of Derby.

Ngima, W. M. \& Kyongo, J. (2013). Contribution of motivational management to employee performance. International Journal of Humanities and Social Science, 3(14), 219-239.

Prieto, I. M. \& Pe'rez-Santana, M. P. (2014). Managing innovative work behavior: the role of human resource practices. Personnel Review, 43(2), 184-208.

Rank, J. (2006). Leadership predictors of proactive organizational behavior: Facilitating personal initiative, voice behavior, and exceptional service performance. $\mathrm{PhD}$ Thesis, Department of Psychology, College of Arts and Sciences, University of South Florida.

Rosen, C. C., Slater, D. J., \& Johnson, R. E. (2013). Let's make a deal development and validation of the ex post I-deals scale. Journal of Management, 39(3), 709-742.

Said, A. A., Rasdi, R. M., Samah, B. A., Silong, A. D., \& Sulaiman. Z. (2015). A career success model for academics at Malaysian research universities. European Journal of Training and Development, 39(9), 815-835.

Saragih, S. (2011). The effects of job autonomy on work outcomes: Self efficacy as an intervening variable. International Research Journal of Business Studies, 4(3), 203-215.

Searle, T. P. (2011). A multilevel examination of proactive work behaviors: Contextual and individual differences as antecedents. $\mathrm{PhD}$ Thesis, Faculty of the Graduate College at the University of Nebraska.

Sekaran, U. (2000). Research methods for business: A skill building approach. New York: John Wiley \& Sons, Inc.

Stumpf, S. A. (2007). Stakeholder assessments as a predictor of high potential and promotion to partner in professional service firms. Career Development International, 12(5), 481-497.

Sutton, K. L. (2006). Parenthood and organizational networks: A relational view of the career mobility of working parents. $\mathrm{PhD}$ Thesis, Graduate School of the Ohio State University.

Takahashi, K. (2006). Effects of wage and promotion incentives on the motivation levels of Japanese employees. Career Development International, 11(3), 193-203.

Usman, H. (2008). Manajemen, teori praktik \& riset pendidikan. Jakarta: Bumi Aksara. 
Van Der Zee, W. (2016). Managing high potential employees: The impact of transformational leadership on behavioral outcomes and the moderation effect of role stress. Master thesis, Human Resource Studies Tilburg University School of Social and Behavioral Sciences.

Wan Aishah, W. M. N., Azman, I., \& Raja Rizal Iskandar, R. H. (2015). Employees' proactive as mediator in career development program model. Paper presented at the 2nd CHREST International Conference, 10-11 June, Palm Garden Hotel, IOI Resort, PUTRAJAYA, Malaysia. University Kebangsaan Malaysia.
Wu, C. H. \& Parker, S. K. (2014). The role of leader support in facilitating proactive work behavior: A perspective from attachment theory. Journal of Management (In Press).

Zhang, L. (2014). Empirical study on the relation between transformation leadership and career succes. Management Science and Research, 3(2), 34-39.

Zhao, X., Lynch, J. G., \& Chen, Q. (2010). Reconsidering Baron and Kenny: Myths and truths about mediation analysis. Journal of Consumer Research, 37(3), 197-206. 